\title{
Bone mineral density in patients with multiple sclerosis, hereditary ataxia or hereditary spastic paraplegia after at least 10 years of disease - a case control study
}

Cecilia Smith Simonsen ${ }^{1,2,5^{*}}$, Elisabeth Gulowsen Celius ${ }^{2,6}$, Cathrine Brunborg ${ }^{7}$, Chantal Tallaksen ${ }^{2,5}$, Erik Fink Eriksen ${ }^{4,5}$, Trygve Holmøy ${ }^{3,5}$ and Stine Marit Moen ${ }^{2}$

\begin{abstract}
Background: Although disability is considered the main cause of low bone mineral density (BMD) in multiple sclerosis (MS), other factors related to the disease process or treatment could also be involved. The aim of this study was to assess whether patients with MS are more likely to develop low BMD (osteopenia or osteoporosis) than patients with the non-inflammatory neurological diseases Hereditary Spastic Paraplegia (HSP) and Hereditary Ataxia (HA).

Methods: We performed a case control study comparing BMD (spine, hip and total body) and biochemical measures of bone metabolism in 91 MS patients and 77 patients with HSP or HA, matched for age, gender and disability. Both patient groups had lived with the disease for at least 10 years.

Results: In total $74.7 \%$ of the patients with MS and $75.3 \%$ of the patients with HSP or HA had osteopenia $(-2.5<$ T- score $<-1.0$ ) or osteoporosis (T- score $\leq-2.5$ ) in one or more sites. Osteoporosis was more common in patients with MS than with HSP/HA (44.0 vs 20.8\%, $p=0.001$ ). This difference was not significant after correction for confounders $(p=0.07)$, nor were any of the biochemical markers.

Conclusion: Most patients with disabling neurological diseases like MS and HSP/HA develop osteopenia or osteoporosis. MS patients had osteoporosis more frequently than HA/HSP patients, though the difference was not significant after adjusting for confounders. Osteoporosis and bone health should be considered in all patients with both inflammatory and degenerative chronic neurological diseases.
\end{abstract}

Keywords: Bone Mineral Density, Case control, Hereditary Ataxia, Hereditary Spastic Paraparesis, Multiple Sclerosis, Osteoporosis

\section{Background}

Multiple sclerosis is a chronic demyelinating disease of the central nervous system with a lifelong disease course and increasing physical disability. Patients with longstanding MS also have an increased risk of osteoporosis and fractures due to reduced bone mass and falls [1]. We have earlier found that low bone mass was more

\footnotetext{
* Correspondence: c.s.simonsen@studmed.uio.no

${ }^{1}$ Department of Neurology, Drammen Hospital, Vestre Viken HF, Dronnigsgate 28, 3004 Drammen, Norway

${ }^{2}$ Department of Neurology, Oslo University Hospital, Oslo, Norway

Full list of author information is available at the end of the article
}

prevalent in newly diagnosed patients with MS with no or minor physical disability than in healthy controls [2]. Disability leading to disuse and reduced mechanical loading of bone is likely an important cause of osteoporosis in patients with long-standing MS [3]. Whether other factors contribute to reduced bone mineral density (BMD) is less clear $[4,5]$, though these may include etiologic or pathophysiologic factors shared between MS and osteoporosis. The skeleton harbours the bone marrow where immune competent cells and osteoclasts develop. The inflammatory processes of MS could possibly affect bone homeostasis as several cytokines, receptors, 
signalling molecules and transcription factors seem to be involved both in the pathogenesis of MS and in the differentiation and activation of osteoclasts [2, 6]. Moreover, hypovitaminosis $\mathrm{D}$ is detrimental for bone health and is also considered a risk factor for MS [7]. Different treatments may also contribute to bone loss in MS. Acute MS exacerbations are treated with glucocorticoids, a medication generally known to cause osteoporosis. Transient glucocorticoid pulses in MS have been reported to have no long-term adverse bone effects $[8,9]$, but the role of steroid treatment over time is not settled [5].

Hereditary ataxia (HA) and hereditary spastic paraplegia (HSP) are neurodegenerative disorders, which are thought to have little or no inflammation. HA is characterised by progressive gait and limb ataxia, loss of coordination and disturbances of speech and oculomotor control, whereas HSP is mainly characterized by progressive spasticity and weakness in the lower limbs [10]. There are very few studies focusing on bone health in HSP/HA patients. One small study on Friedreichs ataxia and a case control study on patients with spinocerebellar degeneration (both subtypes of HA) found significantly reduced bone mineral density compared to healthy controls $[11,12]$. HA and HSP affect locomotion to the same extent as MS, but are considered primarily neurodegenerative and are not treated with glucocorticoids. These diseases are therefore relevant for charting the possible impact of inflammation and treatment on bone health in MS. The aim of this study was to compare the occurrence of osteoporosis and osteopenia, and also biochemical parameters of bone metabolism, in patients with HA and HSP with that of MS.

\section{Methods}

\section{Study design and participants}

Due to limited numbers of patients with the noninflammatory neurological diseases HA and HSP, we first recruited 77 patients with HA and HSP identified from a registry at Oslo University Hospital and living within accessible distance from Oslo [10]. We subsequently recruited 91 matched patients with MS according to McDonald [13] or Poser [14] criteria with disease duration over 10 years from the MS clinics at Oslo University Hospital and Akershus University Hospital for this regional case control study. The MS patients were matched to HSP/HA patients by age ( \pm 5 years), gender and level of disability based on the Expanded Disability Status Scale (EDSS) [15]. Only patients that were mobile enough to get on and off the DXA machine bench with minimal assistance were included.

\section{Data collection}

All BMD measurements were done between January and October in 2008. BMD was assessed from DXA- measurements of lumbar spine (anterior-posterior, L1L4), left hip (femoral neck, femoral trochanter and total hip) and total body were performed with the same instrument at Aker Hospital in Oslo (Lunar Prodigy, General Electrics) and analysed using manufacturer specifications and normative data (National Health and Nutrition Examination Survey III population). The machine was calibrated daily according to manufacturer specifications, and control scanning with a phantom was used regularly to avoid drifting of the DXA measurements. Laboratory personnel handled the patients as a part of routine examination and did not have responsibility for analysis of data. The results are expressed as BMD $(\mathrm{g} / \mathrm{cm} 2)$ and T-score (the number of SDs by which a given BMD value differs from the mean reference value for healthy, young adults) (http://www.uptodate.com/contents/bone-density-testing-beyond-the-basics). We used the WHO classification of osteopenia $(-2.5<\mathrm{T}$-score $<-1.0$ ) and osteoporosis (T-score $\leq-2.5$ ) [16]. Anthropometric data was measured simultaneously. Body mass index (BMI) $\geq 25$ was classified as overweight (http:// www.who.int/topics/obesity/en/)-linked. All biochemical measurements were performed as previously described [17]. Briefly, 25(OH)D and $1,25(\mathrm{OH})_{2} \mathrm{D}$ and DBP were measured by radioimmunoassay. Parathyroid hormone (PTH) was measured with non-competitive immunoluminometric assay. Serum bALP was measured by an enzyme immunoassay kit. Serum ionized calcium (iCa), creatinine, and phosphate were measured according to standard laboratory techniques. NTX in the second morning void urine was measured by competitive enzyme immunoassay. All measurements were collected at the same time as the DXA was performed.

All participants filled in a questionnaire concerning previous and current medication, other autoimmune diseases, sun exposure, exercise, dietary supplements, alcohol and smoking. The questionnaires included questions used routinely as a supplement to the DXA scan to register possible confounders with skeletal effects and were returned by mail. A neurologist recorded clinical history and EDSS based on the last clinical assessment in the case files and a phone call immediately prior to the DXA appointment. Self-reported data on medication were compared with hospital files for the patients with MS from Oslo University Hospital. We also calculated an EDSS equivalent for the HSP/HA patients based on the same criteria as MS patients.

\section{Statistical analysis}

Results are expressed as mean \pm standard deviation (SD) or proportion unless otherwise stated. Pearsons $X^{2}$ test for contingency tables was obtained to detect associations between categorical variables. Differences in continuous variables were tested with the independent 
sample $t$-test. Pearsons correlation coefficient ( $\mathrm{r}$ ) was used to analyse correlations between continuous variables. Only variables with significant relationship with both the MS patients versus HSP/HA patients as exposure and BMD (or T-score) as outcome were considered as possible confounders. Adjustments for multiple confounding variables were performed using multivariable linear regression. The possible confounders were analysed as independent variables separately and simultaneously in the regression models. The following outcome variables were analysed as dependent: L1-L4, left femoral total hip, neck and trochanter, total body, PTH, and phosphate. Missing values were not replaced. All statistical analyses were performed using IBM SPSS statistics version 21 (IBM SPSS Inc., Chicago, IL), and findings were considered significant if $p<0.05$.

\section{Results}

The patient characteristics are shown in Table 1. The MS patients were grouped by disease course. There are patients with relapsing remitting MS (RRMS) that are still experiencing relapses, secondary progressive MS (SPMS), which now only have progressive disease and

Table 1 Demographic and anthropometric data on all patients, MS patients and HSP/HA patients

\begin{tabular}{|c|c|c|c|}
\hline & All & MS & $\mathrm{HSP} / \mathrm{HA}$ \\
\hline Number (\%) & $168(100)$ & $91(54.4)$ & $77(45.6)$ \\
\hline Women (\%) & $82(48.8)$ & $46(50.5)$ & $36(46.8)$ \\
\hline $\begin{array}{l}\text { Disease phenotype } \\
(\%)\end{array}$ & & $\begin{array}{l}\text { RRMS } 51 \text { (56.0) } \\
\text { SPMS } 34(37.4) \\
\text { PPMS } 6 \text { (6.6) }\end{array}$ & $\begin{array}{l}\text { HSP } 61 \text { (79.2) } \\
\text { HA } 12 \text { (15.6) } \\
\text { HSP w/ataxia } \\
4 \text { (5.2) }\end{array}$ \\
\hline Age (SD) & $55.3( \pm 10.4)$ & $52.0( \pm 10.3)$ & $52.7( \pm 10.6)$ \\
\hline $\begin{array}{l}\text { Disease duration } \\
>20 \text { years (\%) }\end{array}$ & $93(55.4)$ & $46(50.5)^{a}$ & $47(61.0)$ \\
\hline $\begin{array}{l}\text { Years since onset } \\
\text { (SD) }\end{array}$ & $24.2( \pm 12.8)$ & $21.3( \pm 9.0)^{a}$ & $27.7( \pm 15.4)$ \\
\hline \multicolumn{4}{|l|}{ Disability (SD) } \\
\hline No aid & $84(50.0)$ & 49 (53.8) & 35 (45.5) \\
\hline One or two sticks & 65 (38.7) & $31(34.1)$ & $34(44.2)$ \\
\hline In wheel chair & $19(11.3)$ & $11(12.1)$ & $8(10.4)$ \\
\hline EDSS & & $\begin{array}{l}4.9 \text { (median 5.0, } \\
\text { range: } 1.5-8.0 \text { ) }\end{array}$ & \\
\hline Height, cm (SD) & $172.7( \pm 8.6)$ & $173.2( \pm 8.3)$ & $172.1( \pm 8.9)$ \\
\hline Weight, kg (SD) & $74.3( \pm 16.3)$ & $71.8( \pm 14.1)^{\mathrm{a}}$ & $77.2( \pm 18.2)$ \\
\hline BMI Kg/m² (SD) & $24.8( \pm 4.5)$ & $23.9( \pm 4.2)^{a}$ & $25.8( \pm 4.7)$ \\
\hline $\begin{array}{l}\text { Total body fat \% } \\
\text { (SD) }\end{array}$ & $32.3( \pm 8.5)$ & $31.6( \pm 8.5)$ & $33.0( \pm 8.5)$ \\
\hline
\end{tabular}

Abbreviations: EDSS Expanded Disability Status Scale, RRMS relapsing remitting multiple sclerosis, SPMS secondary progressive multiple sclerosis, PPMS primary progressive multiple sclerosis, HSP hereditary spastic paraplegia, $H A$ hereditary ataxia, $B M I$ body mass index

${ }^{a} p<0.05$ (independent sample $t$-test) compared to patients with HSP/HA no relapses, and primary progressive MS (PPMS), which have had progressive disease from the start. The mean EDSS was 4.9 (median 5.0, range 6.5) in the MS group and when applying the same definitions of the expanded disability status score to the HA/HSP group, EDSS was 5.3 (median 6.0, range 5.0). The HA/HSP group had higher mean BMI ( $\left.\beta_{\text {unadj. }}=1.93, p=0.004\right)$ and body weight $\left(\beta_{\text {unadj }}=5.38, p=0.03\right)$ compared to the MS group. This was particularly pronounced among the men where $61 \%$ of HA/HSP patients and $33.3 \%$ of MS patients were overweight or obese $(p=0.01)$ See Fig. 1 .

\section{BMD and T-scores}

Unadjusted BMD and T-scores at each skeletal site are shown in Table 2. There was a tendency towards lower $\mathrm{BMD}$ and T-scores in the spine of patients with MS compared to patients with HA/HSP. The proportion of MS and HSP/HA patients with osteopenia or osteoporosis in at least one skeletal site is shown in Fig. 2. About $75 \%$ in each group exhibited osteopenia or osteoporosis. However, $44.0 \%$ of MS patients had osteoporosis in at least one site compared to $20.8 \%$ of HSP/ HA patients $(p=0.001)$.

The difference between MS and HSP/HA patients' lumbar spine BMD were significant, but not after adjusting for confounders (Additional file 1: Table S1), specifically BMI (Table 3). After controlling for the confounding effects of BMI and fish oil intake, the higher percentage of MS patients with osteoporosis compared to HSP/HA patients was no longer significant $(p=0.07)$.

\section{Biochemical markers of bone metabolism}

MS patients exhibited significantly lower PTH ( $\beta_{\text {unadj. }}=$ 1.0, $p=0.002)$ and significantly higher phosphate $\left(\beta_{\text {unadj. }}\right.$ $=0.07, p=0.009)$ compared to HSP $/$ HA. However, after adjustment for the confounding effect of corticosteroid use, disease duration, BMI and alcohol use, the

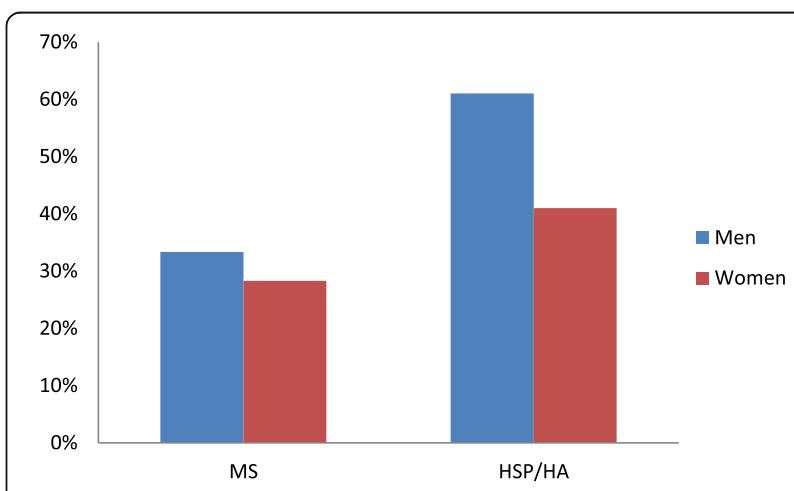

Fig. 1 Percentage of MS patients and HSP/HA patients $s$ with BMl (Body Mass Index) $\geq 25$ (overweight or obese) by gender 
Table 2 BMD and T-scores. Four patients (2 with MS and 2 with $\mathrm{HSP} / \mathrm{HA}$ ) had hip replacements in the left hip and DXA was performed on the right side. Three patients did not have DXA measurements of either hip (1 MS patient with bilateral hip implants and 2 HSP/HA patient with either bilateral hip implants or implant in right hip and rotation osteotomia of the left hip), thus findings in hips only include $90 \mathrm{MS}$ patients and 75 controls

\begin{tabular}{|c|c|c|}
\hline Measurement & $\operatorname{MS}(n=91)$ & $\mathrm{HSP} / \mathrm{HA}(n=77)$ \\
\hline \multicolumn{3}{|l|}{ L1-L4 } \\
\hline $\mathrm{BMD}, \mathrm{g} / \mathrm{cm}^{2}$ & $1.07 \pm 0.18$ & $1.13 \pm 0.16$ \\
\hline T-score & $-1.09 \pm 1.51$ & $-0.59 \pm 1.31$ \\
\hline \multicolumn{3}{|c|}{ L femoral total hip } \\
\hline $\mathrm{BMD}, \mathrm{g} / \mathrm{cm}^{2}$ & $0.86 \pm 0.17$ & $0,90 \pm 0.16$ \\
\hline T-score & $-1.49 \pm 1.40$ & $-1.17 \pm 1.22$ \\
\hline \multicolumn{3}{|l|}{ L femoral neck } \\
\hline BMD, $\mathrm{g} / \mathrm{cm}^{2}$ & $0.84 \pm 0.15$ & $0.87 \pm 0.15$ \\
\hline T-score & $-1.43 \pm 1.26$ & $-1.22 \pm 1.21$ \\
\hline \multicolumn{3}{|c|}{ L femoral trochanter } \\
\hline$B M D, g / \mathrm{cm}^{2}$ & $0.69 \pm 0.16$ & $0.73 \pm 0.16$ \\
\hline T-score & $-1.56 \pm 1.45$ & $-1.20 \pm 1.30$ \\
\hline \multicolumn{3}{|l|}{ Total body } \\
\hline $\mathrm{BMD}, \mathrm{g} / \mathrm{cm}^{2}$ & $1.12 \pm 0.11$ & $1.15 \pm 1.12$ \\
\hline T-score & $-0.6 \pm 1.40$ & $-0.31 \pm 1.33$ \\
\hline
\end{tabular}

Abbreviations: $B M D$ bone mineral density

difference in PTH and phosphate was no longer significant (Table 4).

\section{Discussion}

The main finding in this study was that low bone mass was prevalent in both MS patients and HSP/HA patients, with osteoporosis being twice as common in the

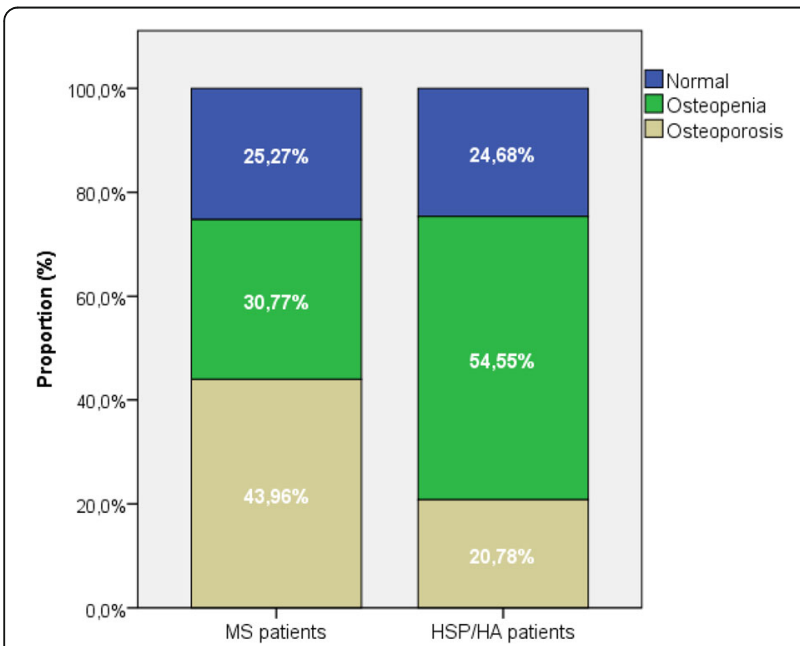

Fig. 2 Proportion of patients with osteopenia $(-2.5<\mathrm{T}$ - score $<-1.0)$ and osteoporosis (T-score $\leq-2.5)$ in at least one site compared to HSP/HA patients
MS group. There were however no significant differences between the two patient groups after adjusting for relevant confounders.

Our study focused on the bone mass of patients with long-standing disease, but still mobile enough to get on a bench with minimal assistance. A broad approach by including measurements of $\mathrm{BMD}$, biochemical parameters and registering possible confounders with skeletal effects was used to address possible factors involved in the bone loss in these patients in the course of disease.

BMD is influenced by a number of factors, including gender, age, ethnicity, BMI, smoking, physical exercise, vitamin D and certain drugs [18]. Our study highlights the importance of checking and adjusting for confounders when studying bone health in MS. There is a well-known association between body mass index (BMI) and bone mineral density [19-21] and although numerous studies have proven that MS patients have lower bone mineral density compared to $\mathrm{HSP} / \mathrm{HA}$ patients [22-24], not all studies have adjusted for body weight or body size in the analysis $[25,26]$. According to the Norwegian institute of public health (http://www.fhi.no/ eway/default.aspx?pid=239\&trg=Content_6496\&Main_6 $157=6263: 0: 25,6306 \&$ MainContent_6263=6496:0:25,6313 \&Content_6496=6178:54371:25,6313:0:6562:16:::0:0) 2/3 of Norwegian 40-42 year olds were overweight or obese (65\% of men and $44 \%$ of women). HSP/HA patients were thus representative (61\% of $\mathrm{HSP} / \mathrm{HA}$ men and $41 \%$ of HSP/HA women were overweight or obese). The MS patients on the other hand were slimmer as only $33.3 \%$ of men and $28.3 \%$ of women had BMI $>25$. We know that a high BMI in childhood and adolescence is associated with a higher risk of MS [27, 28], but this is less obvious in patients with established MS [29]. The fact that patients with MS were slimmer than those with HSP and HA could reflect underlying differences in the pathogenesis of the diseases.

The biochemical markers of bone turnover and metabolism did not differ significantly between these MS patients and HA/HSP patients with over 10 years of disease. It is worth noting that these blood tests represent a snap shot of the dynamics of current bone metabolism, and do not, as BMD, reflect prior bone metabolism over time. However, the bone deficit found in our patients is unlikely to be due to recent increases in bone turnover.

Both HSP/HA patients and MS patients had a long disease history with mean disease duration exceeding 20 years. One limiting factor in MS and HSP/HA patient selection was that only patients who were mobile enough to independently get on and off the bench of the DXA machine were included. This entailed a selection towards the more mobile MS, HA and HSP patients. $50.0 \%$ did not use any walking aid $(53.8 \%$ in the MS 
Table 3 Differences in T-scores between MS patients and HSP/HA patients, with and without adjustment for confounders using linear regression analysis

\begin{tabular}{|c|c|c|c|c|c|c|}
\hline \multirow[b]{2}{*}{ Measurement } & \multicolumn{3}{|c|}{ Unadjusted } & \multicolumn{3}{|c|}{ Adjusted $^{\mathrm{a}}$} \\
\hline & B & $95 \% \mathrm{Cl}$ for $\beta$ & $p$ value & $B$ & $95 \% \mathrm{Cl}$ for $\beta$ & $p$ value \\
\hline L1-L4 & 0.51 & $0.07,0.94$ & 0.02 & 0.32 & $-0.17,0.80$ & 0.20 \\
\hline L femoral total hip & 0.32 & $-0.09,0.76$ & 0.13 & 0.15 & $-0.28,0.58$ & 0.50 \\
\hline L femoral neck & 0.22 & $-0.16,0.60$ & 0.26 & 0.12 & $-0.90,0.525$ & 0.58 \\
\hline L femoral trochanter & 0.36 & $-0.06,0.79$ & 0.10 & 0.22 & $-0.24,0.68$ & 0.35 \\
\hline Total body & 0.29 & $-0.13,0.71$ & 0.17 & 0.07 & $-0.37,0.51$ & 0.76 \\
\hline
\end{tabular}

Abreviations: $\beta$ unstandardised regression coefficient

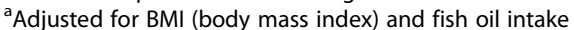

group and $45.5 \%$ in the HSP/HA group), a fairly low number in patients with disease duration above 20 years [30]. EDSS was 4.9 in the MS group and equivalent to 5.3 in the HSP/HA patients. Although we did not examine all the patients ourselves as we relied on recent clinical examinations noted in the patient case journal and additional phone calls to the patients prior to DXA appointment, we believe that this dual approach gave reliable data on EDSS and disability. Studies have shown that scoring EDSS can be done reliably by telephone, especially in patients with a higher EDSS, like our patients [31].

More MS patients had used corticosteroids compared to patients with $\mathrm{HSP} / \mathrm{HA}$, but only $3 \mathrm{MS}$ patients reported more than five pulsed steroid courses during their life-time. The amount of steroids used is difficult to assess exactly retrospectively. We had to rely on the patients reporting steroid treatment in the questionnaire, which is subject to recall bias. These self-reported data were compared with hospital files where possible to increase the validity. The vast majority of our patients had not been exposed to large amounts of corticosteroids, and as expected from previous studies on the effect of steroid pulses on BMD in MS [8,9], steroid use was not associated with BMD. Thus, steroid use is unlikely to be the cause of low bone mass.

We have previously shown that low bone mass was more prevalent in patients with newly diagnosed MS and clinically isolated syndrome (CIS) with no or minor physical disability compared to healthy controls [2] suggesting that etiological factors such as hypovitaminosis $\mathrm{D}$ affect BMD or that MS may affect bone haemostasis

Table 4 Comparing biochemical measures in MS patients and control patients (HSP/HA) with P-values, both unadjusted and adjusted

\begin{tabular}{|c|c|c|c|c|c|c|}
\hline & MS & $\mathrm{HSP} / \mathrm{HA}$ & $\begin{array}{l}\text { Unadjusted } \\
\beta(95 \% \mathrm{Cl})\end{array}$ & $P$-value & $\begin{array}{l}\text { Adjusted } \\
\beta(95 \% \mathrm{Cl})\end{array}$ & $P$-value \\
\hline $25(\mathrm{OH}) \mathrm{D}$ & $77.5 \pm 28.9$ & $70 \pm 26.2$ & $-7.5(15.9,1.0)$ & 0.08 & $-7.5(15.9,1.0)$ & 0.08 \\
\hline $1,25(\mathrm{OH})_{2} \mathrm{D}$ & $139.8 \pm 55.9$ & $129.0 \pm 36.2$ & $-10.8(-25.4,3.9)$ & 0.2 & $-10.8(-25.4,3.9)$ & 0.2 \\
\hline PTH & $3.7 \pm 2.0$ & $4,7 \pm 2.0$ & $1.0(0.4,1.6)$ & 0.002 & $0.17(-0.6,1.0)$ & $0.7^{*}$ \\
\hline $\mathrm{iCa}$ & $1.3 \pm 0.1$ & $1.3 \pm 0.1$ & $0.0(-0.01,0.01)$ & 0.8 & $0.0(-0.01,0.01)$ & 0.8 \\
\hline Phosphate & $1.1 \pm 0.2$ & $1.0 \pm 0.2$ & $-0.1(-1.2,0.02)$ & 0.009 & $0.0(-0.1,0.1)$ & $0.8^{* *}$ \\
\hline DBP & $4.2 \pm 0.6$ & $4.3 \pm 0.8$ & $0.1(-0.1,0.3)$ & 0.5 & $0.1(-0.1,0.3)$ & 0.5 \\
\hline Creat & $67.7 \pm 12.8$ & $70.6 \pm 14.4$ & $2.9(-1.3,7.0)$ & 0.2 & $2.9(-1.3,7.0)$ & 0.2 \\
\hline bALP & $23.4 \pm 8.2$ & $25.0 \pm 6.1$ & $1.6(-0.6,3.8)$ & 0.2 & $1.6(-0.6,3.8)$ & 0.2 \\
\hline NTX & $46.8 \pm 20.9$ & $54.1 \pm 36.3$ & $7.3(-1.7,16.2)$ & 0.1 & $7.3(-1.7,16.2)$ & 0.1 \\
\hline Total Ca & $2.4 \pm 0.1$ & $2.4 \pm 0.1$ & $0.0(-0.01,0.01)$ & 0.9 & $0.0(-0.01,0.01)$ & 0.9 \\
\hline Albumin & $44.9 \pm 2.4$ & $45.3 \pm 2.5$ & $0.4(-0.4,1.1)$ & 0.3 & $0.4(-0.4,1.1)$ & 0.3 \\
\hline TSH & $1.3 \pm 0.7$ & $1.3 \pm 0.6$ & $0.0(-0.2,0.2)$ & 0.9 & $-0.0(-0.2,0.2)$ & 0.9 \\
\hline
\end{tabular}

Some variables have missing values due to technical errors (number of missing patients in parentheses): iCalcium (2), total Ca (2), phosphate (3), creatinin (3), albumin (3), thyroid stimulating hormone (TSH) and NTX (2) from MS patients and PTH (1), iCa (1), total Ca (1), phosphate (2), albumin (1) and NTX (2) from HA/HSP patients

Abbreviations: 25(OH)D 25-hydroxyvitamin D, 1,25(OH) 2 1,25-dihydroxyvitamin D (active vitamin D metabolite), $P T H$ parathyroid hormone, iCa ionized calcium, $D B P$ vitamin D binding protein, $b A L P$ bone specific alkaline phosphatase, NTX cross linked N-terminal telopeptide of type 1 collagen, Ca calcium, TSH thyroid stimulating hormone

${ }^{*}$ Adjusted for corticosteroid use, disease duration and alcohol use

${ }^{* *}$ Adjusted for corticosteroid and BMI 
through inflammatory activity. It is a limitation of our study that we did not measure inflammatory markers, which may reflect disease activity in MS. As for vitamin $\mathrm{D}$, these would however provide limited information about previous levels that is likely more relevant for BMD. However, if inflammation was a major driver of bone loss in MS, we would expect MS patients to have lower BMD compared to disability matched HSP/HA patients as HSP/HA is a non-inflammatory neurodegenerative disease with similar neurological symptoms. One explanation could be that the majority of our MS patients had developed a disease driven primarily by degeneration and less by inflammation. Some claim that during the later stages of the disease the remaining inflammation becomes trapped behind a closed or repaired blood-brain barrier and is not derived peripherally [32]. Our current results may indirectly suggest that the systemic inflammation in MS is not sufficient to increase bone loss over time as is seen in other diseases in which systemic inflammation dominates, such as inflammatory bowel disease [33]. Another possible explanation for the lack of significant difference between MS and HSP/HA patients could be that inflammation may also play a role in HSP/HA. The role of cytokines and microglia in spinocerebellar ataxias is just beginning to be investigated, with promising perspectives [34-36]. The role of inflammation in hereditary neurodegenerative disorders warrants more studies [37].

Although inflammation may be an integral part of bone loss in early MS, this may be only one of many factors behind bone depletion as the patient becomes more disabled. The findings of reduced BMD in MS patients are similar to that found in patients with other noninflammatory, neurological disorder including stroke $[38,39]$. As the level of disability in both MS patients and HSP/HA patients was fairly equal in our study, immobility is likely the main reason for high levels of osteoporosis and osteopenia in both groups.

Regardless of the mechanism, both patient groups have a high rate of osteoporosis and osteopenia and patients with MS had higher prevalence of osteoporosis than those with HSP/HA. According to the WHO, 15\% of all Caucasians between 50 and 59 have osteoporosis [39-41] (http://www.who.int/chp/topics/rheumatic/en/) [40]. One study from Oslo found that $14-36 \%$ of women older than 50 years of age had osteoporosis [41]. In our study $33 \%$ of all patients (MS and HSP/HA patients) had osteoporosis and their age range was 24 to 79 (mean 52). If only looking at female patients aged 50 or older, $(n=46)$, this number rose to $52.2 \%$. Osteoporosis is considered a major risk factor for fractures. One Danish registry study found an incidence rate of any fracture yielded 22.8 per 1000 person-years [42], and several studies confirm the increased risk of fractures in MS patients $[1,43,44]$. The patients are generally less mobile, have poorer balance and a high risk of falling [45] compared to healthy controls. One study found that more than $50 \%$ of 700 MS patients aged 55 years or older reported injurious falls, $12 \%$ within the last 6 months [46]. Patients with HSP are also at an increased risk of falls [47]. There are few studies on fracture risks in this patient group, though one case control study found that $24 \%$ of patients with spinocerebellar degeneration had at least one fracture over a 10 year period compared to $3 \%$ in healthy controls [12]. Regardless of cause, osteoporosis is a big public health problem. Fractures are associated with significantly reduced quality of life through pain, suffering and disability while hip fractures can cause death [48]. Our study highlights the importance of considering bone health in all patients with chronic, disabling neurological disease.

\section{Conclusion}

Most patients with disabling neurological diseases develop osteopenia or osteoporosis. We did a case control study comparing bone mineral density and biochemical measures of bone metabolism in MS patients and patients with HSP or HA, matched for age, gender and disability. MS patients had osteoporosis more frequently than HA/HSP patients, though the difference was not significant after adjusting for confounders. Osteoporosis and bone health should be considered in all patients with both inflammatory and degenerative chronic neurological diseases.

\section{Additional file}

Additional file 1: Supplementary Table 1: an overview of possible bone influential factors in both groups. (DOCX $14 \mathrm{~kb}$ )

\section{Abbreviations}

1.25(OH)2D: 1,25-dihydoxyvitamin D (active vitamin D metabolite); 25(OH)D: 25-hydroxyvitamin D; B: Unstandardised regression coefficient; bALP: Bone specific alkaline phosphatase; BMD: Bone mineral density; BMI: Body mass index; Ca: Calcium; CIS: Clinically isolated syndrome; DBP: Vitamin D binding protein; DXA: Dual-energy X-ray absorptiometry; EDSS: Expanded disability status scale; HA: Hereditary ataxi; HSP: Hereditary spastic paraplegia; iCa: Ionized calcium; MS: Multiple sclerosis; NTX: Cross linked N-terminal telopeptide of type 1 collagen; PTH: Parathyroid hormone; SCA: Spinocerebellar ataxia; SD: Standard deviation; TSH: Thyroid stimulating hormone; WHO: World health organisation

\section{Acknowledgements}

The authors would like to thank the patients for participating in this study. We would also like to extend our gratitude to Drs Elena Didenko Pedersen, Cathrine Smestad, Anne Kjersti Erichsen, Jeanette Koht and Iselin Marie Wedding for help in recruiting patients, and Dr Jan A. Falch and the DXA technicians at Aker hospital for taking part in the study.

Funding

The study was funded by grants from the South Eastern Norway Health Authority.

Availability of data and materials

Our data is stored in a secure hospital research server at Oslo University Hospital. The HSP/HA patients in the Oslo region are a small and easily 
recognisable group. The dataset contains detailed information that may compromise patient confidentiality and will therefore not be made available.

\section{Authors' contributions}

SMM collected the data, participated in the design of the study and drafted the manuscript. CSS carried out and interpreted the statistical analyses, and drafted the manuscript. EGC participated in the conception and design of the study and drafted the manuscript. TH participated in the conception and design of the study. CB participated in the statistical analysis. EFE participated in the design of the study. CT helped recruit patients. All authors read and approved the final manuscript.

\section{Competing interests}

CSS has received funding from The Odd Fellow Research Fund for Multiple Sclerosis as well as travel and speakers fees from Biogen Idec. EGC has received funding for travel and speaker's fees from Sanofi-Aventis, Merck Serono, Genzyme, Biogen Idec, Teva, Almirall and Novartis, and received unrestricted research support from Biogen Idec and Novartis. CB has no conflicts of interest. EFE has no conflicts of interest. CT has no conflicts of interest. TH has received speaker's honoraria and research grants from Novartis, Biogen Idec, Merc Serono, Sanofi-Aventis, and Genzyme. SMM has received one unrestricted travel support and unrestricted research grant from Biogen Idec and unrestricted research grant and speaker's honoraria from Novartis.

\section{Consent for publication}

Consent for publication was obtained from all participants as a part of the written informed consent for study participation.

\section{Ethics approval and consent to participate}

The study was approved by the Regional Committee for Research Ethics in South-Eastern Norway Regional Health Authority and the Review board for Oslo University Hospital Ullevål. Written informed consent was obtained from all participants. Patients with osteoporosis and osteopenia were evaluated by an osteoporosis specialist and offered advice and treatment.

\section{Author details}

'Department of Neurology, Drammen Hospital, Vestre Viken HF, Dronnigsgate 28, 3004 Drammen, Norway. ${ }^{2}$ Department of Neurology, Oslo University Hospital, Oslo, Norway. ${ }^{3}$ Department of Neurology, Akershus University Hospitals, Oslo, Norway. ${ }^{4}$ Department of Endocrinology, Morbid Obesity and Preventive Medicine, Oslo University Hospital, Oslo, Norway. ${ }^{5}$ Institute of Clinical Medicine, Faculty of Medicine, University of Oslo, Oslo, Norway. ${ }^{6}$ Institute of Health and Society, Faculty of Medicine, University of Oslo, Oslo, Norway. ${ }^{7}$ Oslo Centre for Biostatistics and Epidemiology, Research Support Services, Oslo University Hospital, Oslo, Norway.

\section{Received: 4 June 2016 Accepted: 23 November 2016}

\section{Published online: 05 December 2016}

\section{References}

1. Cosman F, Nieves J, Komar L, Ferrer G, Herbert J, Formica C, et al. Fracture history and bone loss in patients with MS. Neurology. 1998;51(4):1161-5.

2. Moen SM, Celius EG, Sandvik L, Nordsletten L, Eriksen EF, Holmoy T. Low bone mass in newly diagnosed multiple sclerosis and clinically isolated syndrome. Neurology. 2011;77(2):151-7.

3. Gibson JC, Summers GD. Bone health in multiple sclerosis. Osteoporos Int 2011;22(12):2935-49.

4. Hearn AP, Silber E. Osteoporosis in multiple sclerosis. Mult Scler. 2010;16(9): 1031-43.

5. Gupta S, Ahsan I, Mahfooz N, Abdelhamid N, Ramanathan M, WeinstockGuttman B. Osteoporosis and multiple sclerosis: risk factors, pathophysiology, and therapeutic interventions. CNS Drugs. 2014;28(8):731-42.

6. Takayanagi H. Osteoimmunology: shared mechanisms and crosstalk between the immune and bone systems. Nat Rev Immunol. 2007;7(4):292-304.

7. Ascherio A, Munger KL, Simon KC. Vitamin D and multiple sclerosis. Lancet Neurol. 2010;9(6):599-612.

8. Zorzon M, Zivadinov R, Locatelli L, Giuntini D, Toncic M, Bosco A, et al. Long-term effects of intravenous high dose methylprednisolone pulses on bone mineral density in patients with multiple sclerosis. Eur J Neurol. 2005; 12(7):550-6.
9. Ravnborg M, Sorensen PS, Andersson M, Celius EG, Jongen PJ, Elovaara I, et al. Methylprednisolone in combination with interferon beta-1a for relapsing-remitting multiple sclerosis (MECOMBIN study): a multicentre, double-blind, randomised, placebo-controlled, parallel-group trial. Lancet Neurol. 2010;9(7):672-80.

10. Erichsen AK, Koht J, Stray-Pedersen A, Abdelnoor M, Tallaksen CM. Prevalence of hereditary ataxia and spastic paraplegia in southeast Norway: a population-based study. Brain. 2009;132(Pt 6):1577-88.

11. Eigentler A, Nachbauer W, Donnemiller E, Poewe W, Gasser RW, Boesch S. Low bone mineral density in friedreich ataxia. Cerebellum (London, England). 2014;13(5):549-57.

12. Sato $Y$, Honda $Y$, Asoh $T$, Iwamoto J. Longitudinal study of bone and calcium metabolism and fracture incidence in spinocerebellar degeneration. Eur Neurol. 2006;56(3):155-61.

13. Polman $\mathrm{CH}$, Reingold SC, Edan G, Filippi M, Hartung HP, Kappos L, et al. Diagnostic criteria for multiple sclerosis: 2005 revisions to the "McDonald criteria". Ann Neurol. 2005:58(6):840-6.

14. Poser CM, Paty DW, Scheinberg L, McDonald WI, Davis FA, Ebers GC, et al. New diagnostic criteria for multiple sclerosis: guidelines for research protocols. Ann Neurol. 1983;13(3):227-31.

15. Kurtzke JF. Rating neurologic impairment in multiple sclerosis: an expanded disability status scale (EDSS). Neurology. 1983;33(11):1444-52.

16. Assessment of fracture risk and its application to screening for postmenopausal osteoporosis. Report of a WHO Study Group. World Health Organization technical report series. 1994;843:1-129.

17. Moen SM, Celius EG, Sandvik L, Brustad M, Nordsletten L, Eriksen EF, et al. Bone turnover and metabolism in patients with early multiple sclerosis and prevalent bone mass deficit: a population-based case-control study. PLoS One. 2012;7(9):e45703.

18. Nasjonale faglige retningslinjer for forebygging og behandling av osteoporose og osteoporotiske brudd https://www.google.no/url?sa=t\&rct=j\&q=\&esrc= s\&source $=$ web\&cd=3\&ved=0ahUKEwilpLfeONPQAhXEL8AKHW3BCPoQFggn MAI\&url=https\%3A\%2F\%2Ffysio.no\%2Fcontent\%2Fdownload\%2F5180\%2F 131091\%2Fversion\%2F1\%2Ffile\%2FNasjonal-faglige-retningslinje-for-foreby gging-og-behandling-av-osteoporose-og-osteoporotiske-brudd-IS-1322.pdf\& usg=AFQjCNHB-8-FH5AW7 DtGQZqQKMPH7Jg9w\&bvm=bv.139782543,d.d24

19. Andreoli A, Bazzocchi A, Celi M, Lauro D, Sorge R, Tarantino U, et al. Relationship between body composition, body mass index and bone mineral density in a large population of normal, osteopenic and osteoporotic women. Radiol Med. 2011;116(7):1115-23.

20. El Hage R, Jacob C, Moussa E, Groussard C, Pineau JC, Benhamou CL, et al. Influence of the weight status on bone mineral content and bone mineral density in a group of Lebanese adolescent girls. Joint Bone Spine. 2009;76(6):680-4.

21. Schlussel MM, Vaz JS, Kac G. Birth weight and adult bone mass: a systematic literature review. Osteoporos Int. 2010;21(12):1981-91.

22. Sioka C, Papakonstantinou S, Fotopoulos A, Alamanos Y, Georgiou A, Tsouli $\mathrm{S}$, et al. Bone mineral density in ambulatory patients with multiple sclerosis. Neurol Sci. 2011;32(5):819-24

23. Weinstock-Guttman B, Gallagher E, Baier M, Green L, Feichter J, Patrick K, et al. Risk of bone loss in men with multiple sclerosis. Mult Scler. 2004;10(2):170-5.

24. Huang Z, Qi Y, Du S, Chen G, Yan W. BMI levels with MS bone minera density levels in adults with multiple sclerosis: a meta-analysis. Int J Neurosci. 2015:125(12):904-12.

25. Nieves J, Cosman F, Herbert J, Shen V, Lindsay R. High prevalence of vitamin $D$ deficiency and reduced bone mass in multiple sclerosis. Neurology. 1994;44(9):1687-92.

26. Ozgocmen S, Bulut S, Ihan N, Gulkesen A, Ardicoglu O, Ozkan Y. Vitamin D deficiency and reduced bone mineral density in multiple sclerosis: effect of ambulatory status and functional capacity. J Bone Miner Metab. 2005;23(4): 309-13.

27. Munger KL, Bentzen J, Laursen B, Stenager E, Koch-Henriksen N, Sorensen TI, et al. Childhood body mass index and multiple sclerosis risk: a long-term cohort study. Mult Scler. 2013;19(10):1323-9.

28. Munger $\mathrm{KL}$, Chitnis T, Ascherio A. Body size and risk of MS in two cohorts of US women. Neurology. 2009;73(19):1543-50

29. Pinhas-Hamiel O, Livne M, Harari G, Achiron A. Prevalence of overweight, obesity and metabolic syndrome components in multiple sclerosis patients with significant disability. Eur J Neurol. 2015:22(9):1275-9.

30. Weinshenker BG, Bass B, Rice GP, Noseworthy J, Carriere W, Baskerville J, et al. The natural history of multiple sclerosis: a geographically based study. I. Clinical course and disability. Brain. 1989;112(Pt 1):133-46. 
31. Lechner-Scott J, Kappos L, Hofman M, Polman CH, Ronner H, Montalban X et al. Can the expanded disability status scale be assessed by telephone? Mult Scler. 2003;9(2):154-9.

32. Lassmann $\mathrm{H}$, van Horssen J, Mahad D. Progressive multiple sclerosis: pathology and pathogenesis. Nat Rev Neurol. 2012;8(11):647-56.

33. Lim H, Kim HJ, Hong SJ, Kim S. Nutrient intake and bone mineral density by nutritional status in patients with inflammatory bowel disease. J Bone Metab. 2014;21(3):195-203.

34. Evert BO, Vogt IR, Kindermann C, Ozimek L, de Vos RA, Brunt ER, et al. Inflammatory genes are upregulated in expanded ataxin-3-expressing cell lines and spinocerebellar ataxia type 3 brains. J Neurosci. 2001;21(15):5389-96.

35. Giovannoni R, Maggio N, Rosaria Bianco M, Cavaliere C, Cirillo G, Lavitrano $M$, et al. Reactive astrocytosis and glial glutamate transporter clustering are early changes in a spinocerebellar ataxia type 1 transgenic mouse model. Neuron Glia Biol. 2007:3(4):335-51.

36. Custer SK, Garden GA, Gill N, Rueb U, Libby RT, Schultz C, et al. Bergmann glia expression of polyglutamine-expanded ataxin-7 produces neurodegeneration by impairing glutamate transport. Nat Neurosci. 2006; 9(10):1302-11.

37. Olejniczak M, Urbanek MO, Krzyzosiak WJ. The role of the immune system in triplet repeat expansion diseases. Mediat Inflamm. 2015;2015:873860.

38. Jorgensen $L$, Jacobsen BK, Wilsgaard T, Magnus JH. Walking after stroke: does it matter? changes in bone mineral density within the first 12 months after stroke. A longitudinal study. Osteoporos Int. 2000;11(5):381-7.

39. Dobson R, Yarnall A, Noyce AJ, Giovannoni G. Bone health in chronic neurological diseases: a focus on multiple sclerosis and parkinsonian syndromes. Pract Neurol. 2013;13(2):70-9.

40. "Chronic rheumatic conditions". World Health Organization. Retrieved 18 May 2015.

41. Falch JA, Meyer HE. Osteoporosis and fractures in Norway. Occurrence and risk factors. Tidsskr Nor Laegeforen. 1998;118(4):568-72.

42. Bazelier MT, Bentzen J, Vestergaard P, Stenager E, Leufkens HG, van Staa TP, et al. The risk of fracture in incident multiple sclerosis patients: the Danish National Health Registers. Mult Scler. 2012;18(11):1609-16.

43. Dong G, Zhang N, Wu Z, Liu Y, Wang L. Multiple sclerosis increases fracture risk: a meta-analysis. Biomed Res Int. 2015;2015:650138.

44. Bazelier MT, van Staa TP, Uitdehaag BM, Cooper C, Leufkens HG, Vestergaard $\mathrm{P}$, et al. Risk of fractures in patients with multiple sclerosis: a population-based cohort study. Neurology. 2012;78(24):1967-73.

45. Matsuda PN, Shumway-Cook A, Bamer AM, Johnson SL, Amtmann D, Kraft GH. Falls in multiple sclerosis. PM R. 2011;3(7):624-32. quiz 32.

46. Peterson EW, Cho CC, von Koch L, Finlayson ML. Injurious falls among middle aged and older adults with multiple sclerosis. Arch Phys Med Rehabil. 2008:89(6):1031-7.

47. Nonnekes J, de Niet M, Oude Nijhuis LB, de Bot ST, van de Warrenburg BP Bloem BR, et al. Mechanisms of postural instability in hereditary spastic paraplegia. J Neurol. 2013;260(9):2387-95.

48. Johnell O, Kanis J. Epidemiology of osteoporotic fractures. Osteoporos Int 2005;16 Suppl 2:S3-7.

\section{Submit your next manuscript to BioMed Central and we will help you at every step:}

- We accept pre-submission inquiries

- Our selector tool helps you to find the most relevant journal

- We provide round the clock customer support

- Convenient online submission

- Thorough peer review

- Inclusion in PubMed and all major indexing services

- Maximum visibility for your research

Submit your manuscript at www.biomedcentral.com/submit

) Biomed Central 